\title{
Urgences
}

\section{La serpentine}

\section{Ginette Perron}

Numéro 3, 4e trimestre 1981

URI : https://id.erudit.org/iderudit/025044ar

DOI : https://doi.org/10.7202/025044ar

Aller au sommaire du numéro

Éditeur(s)

Urgences

ISSN

0226-9554 (imprimé)

1927-3924 (numérique)

Découvrir la revue

Citer ce document

Perron, G. (1981). La serpentine. Urgences, (3), 49-53.

https://doi.org/10.7202/025044ar

Ce document est protégé par la loi sur le droit d'auteur. L'utilisation des services d'Érudit (y compris la reproduction) est assujettie à sa politique d'utilisation que vous pouvez consulter en ligne.

https://apropos.erudit.org/fr/usagers/politique-dutilisation/ 



\section{LA SERPENTINE}

II y a une flèche fulgurante qui se meut inaltérablement à l'intérieur de Martha. Le printemps éclabousse comme une gerbe aux quatre coins de I'horizon. Le corps de Martha se meut aux quatre coins de I'horizon. Le corps de Martha a envie de pourfendre le ciel. C'est la serpentine qui l'habite. Elle tourne comme une furie en cage, Martha, à l'intérieur de son balcon qui domine le paysage de verdure. Le fer forgé est plus pénible à son âme que l'éphémérité du temps qui passe.

Comment vaincre l'espace pour toucher l'essentiel de la vie? “Comment $\mathrm{m}$ 'asseoir tranquille devant la télévision, soir après soir, puis changer le petit écran pour le grand écran de cinéma, puis changer le grand écran pour l'image mobile, quotidienne des hommes, collée à ma fenêtre?" Si les ongles de Martha pouvaient déchirer la fenêtre, celle-ci s'effriterait et formerait un tas de poussières d'argent.

"La vie m'est si essentielle", et son bras dessine une courbe gracieuse dans le soleil. "Encadrer le soleil, dans les pores de mon bras, ne jamais l'éteindre, mais seulement l'étreindre, ô jolies serpentines de soleil au bout de mes doigts." La fureur habite Martha. Le feu comme de petits serpents jaillit de ses pores blanches, lacs troués de symboles phalliques.

"Devrais-je marcher dans le parc au bord de la montagne et y trouver un homme? Le beau serpent en érection! II pourrait apaiser ma brûlure!... Comment $\mathrm{m}^{\prime}$ asseoir au corps d'un homme, soir après soir, sans y trouver un goût de mort? Dépasser la saveur d'ennui pour $\mathrm{m}$ 'anéantir dans la lumière et dans la nuit de son corps? Quelque soit le chemin que je prenne, il me conduit à la mort. C'est une mort d'orgasme ou une mort de vieillesse, 
mais quelle qu'elle soit, je me déchire comme la fenêtre et me ramasse en un tas de poussières d'argent. "Oh, me diras-tu, ta déchirure était belle puisqu'il reste au creux de ma main cette lumière de verre." Mais Martha veut être plus qu'une émanation transparente de diamant ou de pacotille. Rien, non rien, ne peut calmer la serpentine.

Le fer forgé du balcon continue de broyer l'âme de Martha. Ces noirs serpents de métal enveloppent son corps comme la lumière dans le cristal barriolé. Mais le cristal est si dur qu'il faut être transparent pour le traverser. "J'ai les doigts comme des serpentines de feu. Je briserai bien l'ennui." 


\section{LA BELLE AU BOIS DORMANT, NOUVELLE VAGUE}

La couleur de la nuit se disperse

sous I'océan de neige

Frappe à ma porte

homme de la terre de la forêt ou de la mer

Cherche la femme

qui dort en moi

Hier tu courais loin de la maison

chassant pêchant soulevant la terre

pour apporter les fruits à nos enfants

Aujourd'hui c'est moi

courant loin de la maison

chassant pêchant soulevant la terre

pour inventer de nouveaux enfants

Non je ne suis plus

me berçant à ma fenêtre

attendant que la neige cesse

que ton pas revienne

et ta main me caresse

Oui je suis chevauchant les montagnes

brisant les fenêtres

pour trouver ma lumière 
Oui c'est toi qui m'attends

sous l'ampoule éteinte

de notre chambre

avec ton regard brillant

comme un feu d'été

cherchant la femme

qui dort en moi

Non nous ne dormirons plus ensemble comme ont dormi jadis nos ancêtres

toi et ton harpon à ta gauche

moi et mon enfant à ma droite

Enfin enfin nous dormirons ensemble

pour la première fois

le harpon à nos pieds

et notre enfant au milieu de nous

Notre lit est un océan de neige

Donne-moi ta main mon amour

Réveille-toi courons à la fenêtre

Nos doigts sont des flammes rieuses et vivantes

La neige fond sous nos pas

Avec toi je veux allumer tous les soleils de l'univers 